\title{
Saúde e direitos sociais
}

\section{Health and the social rights}

\section{Salud y derechos sociales}

\author{
Rosane Aparecida de Sousa Martins ${ }^{1, a}$ \\ rosane.martins@uftm.edu.br | https://orcid.org/oooo-0002-5943-4175 \\ ${ }^{1}$ Universidade Federal do Triângulo Mineiro, Departamento de Serviço Social. Uberaba, MG, Brasil. \\ a Doutorado em Serviço Social pela Universidade Estadual Paulista.
}

Palavras-chave: Saúde; Direitos sociais; Tecnologia da informação; Internet; Educação em saúde; Comunicação em saúde; Gestão da informação em saúde; Mídias sociais.

Keywords: Health; Social rights; Information technology; Internet; Health education; Health communication; Health information management; Social media.

Palabras clave: Salud; Derechos sociales; Tecnología de la información; Internet; Educación acerca de la salud; Comunicación acerca de la salud; Gestión de la información acerca de la salud; Medios de comunicación sociales.

Os direitos sociais são identificados como direitos que têm como objetivo buscar ou ampliar a qualidade de vida e de trabalho para toda a população, de modo a lhe garantir condições dignas de vida em sociedade.

Historicamente, os direitos sociais foram conquistados a partir de lutas e mobilizações populares visando à superação das iniquidades sociais, da opressão e precarização das condições de vida e de trabalho.

Nesse contexto, destaca-se a Declaração Universal dos Direitos Humanos, de 1948, que completa 70 anos em 2018. Esse documento ratifica o reconhecimento de que as pessoas devem ter acesso a direitos sociais que assegurem a si e à sua família um padrão de vida capaz de garantir o atendimento de suas necessidades e demandas para viverem com dignidade.

Em seu artigo XXV, a Declaração Universal dos Direitos Humanos ${ }^{1}$ aponta que todo ser humano tem entre outros direitos os de alimentação, vestuário, habitação, lazer, educação, cultura, saúde e bem-estar. A Declaração faz menção também a serviços sociais indissociáveis do direito à vida, do princípio da dignidade humana e da solidariedade, como salienta Simões². Segundo este autor, "diante da pobreza e da expropriação, que eram impostas aos trabalhadores, os conceitos de liberdade e de igualdade formais passaram a ser questionados em face da supremacia do valor da solidariedade social, não decorrente do assistencialismo caritativo, mas da divisão social 
do trabalho, posto que, na realidade, havia uma grande distância entre a declaração abstrata dos princípios igualitários e os direitos sociais".

A mobilização e luta da classe trabalhadora pelo acesso aos direitos sociais ocorreu em diversos países, de modo que as reivindicações tinham tanto caráter nacional como internacional. Nesse contexto, Simões ${ }^{2}$ salienta que "Os direitos sociais - como a saúde, a previdência social, as condições especiais de trabalho para as mulheres, os limites de horário de trabalho, a idade mínima das crianças no trabalho e o horário de descanso e lazer, a serem assegurados pelo Estado - foram considerados fundamentais. Não se tratava apenas de enunciar esses direitos nos textos constitucionais, mas de prever mecanismos que assegurassem, aos trabalhadores, sua promoção efetiva, buscando a igualdade real".

Dessa forma, é possível compreender os direitos sociais como mencionado anteriormente e reiterado aqui. Trata-se dos direitos que têm como objetivo buscar ou ampliar a qualidade de vida e de trabalho para toda a população, de modo a lhe garantir condições dignas de vida em sociedade. Historicamente, os direitos sociais foram conquistados a partir de lutas e mobilizações populares visando à superação das iniquidades sociais, da opressão e precarização das condições de vida e de trabalho.

Os direitos sociais, no entanto, são garantias da sociedade civil, com eficácia nas relações privadas, o que retira do Estado qualquer pretensão estatizante ou tutelar, ao mesmo tempo em que delas não se abstém, pois deve tomar a iniciativa de sua efetividade, por meio do poder judiciário e de políticas públicas².

No Brasil. é possível destacar, por exemplo, a aprovação da Constituição Federal (CF) de 1988², chamada de Constituição cidadã, a partir da pressão popular e da mobilização social. O marco sobre a discussão acerca dos direitos sociais na Constituição Federal de 1988 é apresentado especialmente nos títulos sobre direitos e garantias fundamentais e ordem social.

$\mathrm{O}$ artigo $6^{\circ}$ da $\mathrm{CF}$, com a Emenda Constitucional $n^{0} 64$ de 4 de fevereiro de 2010, que introduziu a alimentação como direito social, salienta que "São direitos sociais a educação, a saúde, a alimentação, o trabalho, a moradia, o lazer, a segurança, a previdência social, a proteção à maternidade e à infância, a assistência aos desamparados, na forma desta Constituição"4.

O direito à saúde, por exemplo, foi decorrente, principalmente, da organização e mobilização do chamado movimento da Reforma Sanitária com a participação de profissionais da saúde, organizações sociais e população engajados nos movimentos de lutas pelo acesso à saúde pública, gratuita e universal.

O movimento da Reforma Sanitária promoveu espaço de debates, reflexões e proposições acerca do modelo de sistema de saúde que pudesse atender a toda a população brasileira, independentemente de sua condição e inserção na sociedade. Com isso, um dos mais importantes direitos sociais como o direito à saúde foi assegurado na CF de 1988 e completa 30 anos em 2018.

O acesso à política de saúde é um direito social, que depende também do acesso a outros direitos sociais como educação, alimentação, moradia, trabalho, saneamento básico, segurança pública, cultura, lazer etc. Ou seja, o direito à saúde traz implícita a necessidade de acesso a outros bens, recursos, serviços e equipamentos sociais que garantam a qualidade de vida do homem em sociedade.

Portanto, os direitos sociais precisam estar inseridos no contexto das garantias e dos direitos fundamentais associados aos direitos individuais, direitos coletivos e políticos instituídos e efetivados pelo Estado.

Eis aí o grande desafio. Num contexto de transformações societárias nas quais os interesses do mercado financeiro sobressaem às demandas e necessidades da população brasileira, em especial as da classe trabalhadora, como avançar na efetivação das políticas e direitos sociais conquistados e estabelecidos na Constituição Federal do Brasil de 1988? A população consegue dimensionar os impactos das decisões do governo Temer nas políticas sociais e, particularmente, na política de saúde? Quais são as estratégias e ações que os profissionais da saúde têm desenvolvido para atenderem à proposta de atenção à saúde da população? 
Estudos no âmbito da literacia para a saúde ratificam que um dos mecanismos para avançarmos na efetivação do acesso aos direitos sociais, inclusive no direito à saúde é o conhecimento. Conforme definição de Robinson ${ }^{5}$, "Literacia é a capacidade para identificar, compreender, interpretar, criar, comunicar e usar as novas tecnologias, de acordo com os diversos contextos. A Literacia envolve um processo contínuo de aprendizagem que capacita o indivíduo a alcançar os seus objetivos, a desenvolver os seus potenciais e o seu conhecimento, de modo a poder participar de forma completa na sociedade".

A partir do desenvolvimento dessas capacidades, tanto os profissionais da saúde como a comunidade em geral terão habilidades e competências para fazerem escolhas e também autonomia para realizarem as ações de promoção de saúde e de participação e controle social. Dessa forma, os diversos segmentos da sociedade poderão reivindicar junto ao Estado as políticas, bens e serviços necessários e previstos para atender às demandas da política de saúde e demais políticas importantes para o alcance da dignidade humana.

A Carta de Nairobi ${ }^{6}$ destaca a definição de literacia para a saúde como "o grau em que as pessoas são capazes de acessar, compreender, avaliar e comunicar informações, para envolver-se com as demandas de diferentes contextos, a fim de promover e manter boas condições de saúde ao longo da vida”.

Nessa direção, este número da Reciis convida o leitor a refletir sobre a realidade social e o impacto das transformações societárias no acesso aos direitos sociais, na efetivação das políticas públicas e na garantia de condições de vida digna à população brasileira.

Na seção Notas da conjuntura, que reinicia a publicação de textos em língua estrangeira pela Reciis, Arthur Chioro faz uma abordagem contagiante, crítica, reflexiva e comprometida com a autonomia e emancipação dos cidadãos. $\mathrm{O}$ autor recupera fatos históricos aliados a dados atuais, contextualizando as diversas expressões da questão social que assolam, especialmente, o cotidiano da classe trabalhadora no que tange às políticas e aos direitos sociais.

Os seis artigos originais abordam temas que permeiam a saúde, a sexualidade e também o uso das tecnologias de informação e comunicação em saúde como estratégia para educação em saúde e efetivação do acesso à saúde. Cabe destacá-los: "Rede Brasileira de Bancos de Leite Humano: uma rede baseada na confiança"; "Comunicação terapêutica: desafios para o diálogo em uma organização hospitalar"; "O desenvolvimento das tecnologias de informação e comunicação: efeitos na relação médico-paciente em Portugal"; "Educação em saúde e jornalismo operativo: articulações teórico-metodológicas"; "Mapeamento de pesquisadores precursores da área de prevenção de drogas em contextos educacionais no Brasil"; e "Corpos e percepções de um tempo que passa: reflexões sobre gênero e movimentos do tempo em Sou Mais Eu, Junior e Men's Health Portugal".

Este número da Reciis apresenta ainda dois artigos que enfatizam a comunicação em saúde e a sua interlocução com o acesso à informação, compartilhamento de informações, troca de conhecimentos e experiências como estratégia para a autonomia, liberdade e participação social dos sujeitos. Nesse contexto, encontra-se um relato de experiência, intitulado "Blog como ferramenta educacional: contribuições para o processo interdisciplinar de educação em saúde"; e um artigo de revisão sobre o uso de mídias sociais no campo da saúde com foco na análise de uma delas, denominado "O uso do Facebook na promoção da saúde: uma revisão bibliográfica sobre empoderamento e participação popular".

Também merece destaque a entrevista com o professor doutor Naomar de Almeida Filho, professor titular da Universidade Federal da Bahia (UFBA), na qual o leitor tem acesso a uma importante discussão acerca de sua trajetória e militância na saúde pública assim como a uma problematização de questões atuais extremamente relevantes para fortalecer os princípios e diretrizes do SUS. O entrevistado faz uma análise crítica sobre a política de saúde e sua interface com educação, pesquisa e produção de conhecimentos como estratégias para o enfrentamento da desigualdade em saúde e para a luta contra o desmonte das políticas públicas. 
Assim, este número da Reciis convida o leitor a dialogar e refletir sobre os direitos sociais e sua interlocução com a saúde de forma crítica e propositiva. Boa leitura.

\section{Referências}

1. Unicef (BR). Declaração Universal dos Direitos Humanos [Internet]. Brasilia, DF; 1948 [citado em 07 jun. 2018]. Disponível em: https://www.unicef.org/brazil/pt/resources 10133.htm

2. $\quad$ Simões C. Curso de direito do Serviço Social. 7 ed. São Paulo: Cortez; 2014.

3. Presidência da República (BR). Constituição: República Federativa do Brasil 1988 [Internet]. Brasília (DF); 1988 [citado em 28 maio 2018]. Disponível em: https://www2.senado.leg.br/bdsf/bitstream/ handle/id/518231/CF88 Livro EC91 2016.pdf.

4. Presidência da República (BR). Emenda constitucional n 64, de 4 de fevereiro de 2010. Altera 0 art. $6^{\circ}$ da Constituição Federal, para introduzir a alimentação como direito social. Diário Oficial da União, Brasília (DF); 5 fev. 2010. [citado em 28 maio 2018]. Disponível em: http://www.planalto.gov.br/ ccivil 03/constituicao/emendas/emc/emc64.htm

5. Robinson C. Literacy: New Meanings and Dimensions. Paper presented at: Unesco Expert Meeting: Renewed Vision of Literacy and Policy Implications; 10 June 2003, Paris.

6. World Health Organization. The 7th Global Conference on Health Promotion: promoting health and development closing the implementation gap. Nairobi, Quenia; out. 2009 [acesso em 29 de maio de 2018]. Disponível em: http://www.who.int/healthpromotion/conferences/7gchp/Programme.pdf?ua=1 